\title{
Growth Conditions and Ripening Influence Plastid and Microsomal Membrane Lipid Composition in Bell Pepper Fruit
}

\author{
Bruce D. Whitaker \\ U.S. Department of Agriculture, Agricultural Research Service, Horticultural Crops Quality \\ Laboratory, Beltsville Agricultural Research Center, Beltsville, MD 20705
}

\begin{abstract}
Additional index words. Capsicum annuum, chloroplasts, chromoplasts, galactolipids, pericarp, phospholipids, phytosterols, steryl glycosides

Abstract. Plastids and microsomal membranes were isolated from pericarp tissue of mature-green and red-ripe bell pepper (Capsicum annuиm L.) fruit harvested from greenhouse- and field-grown plants. The lipid composition of these membrane fractions changed much more with ripening of field-grown than greenhouse-grown fruit. Also, the phospholipid (PL), free sterol (FS), steryl glycoside (SG), and acylated steryl glycoside (ASG) content of microsomes and plastids from green and red fruit were very different under the two growing conditions. Total steryl lipids (TSL $=$ FS + SG + ASG) and the TSL: PL ratio increased in microsomes and decreased in plastids with ripening. These changes were much greater in field-grown fruit. The ASG : SG ratio decreased with ripening in both membrane fractions under both growing conditions. Ripening and growth conditions affected the phospholipid and sterol composition in plastids much more than in microsomes. Lipid changes associated with the chloroplast to chromoplast transformation were similar in field- and greenhouse-grown fruit, including an increase in the galactolipid : PL ratio.
\end{abstract}

Changes in steryl lipid content and composition in plant cell membranes, and in the steryl lipid : phospholipid ratio, are thought to play a role in ripening and senescence by altering the physical properties of the lipid matrix and, consequently, the activity of membrane-bound enzymes (Lurie and Ben-Arie, 1983; Thompson et al., 1982; Wojciechowski, 1980). Dramatic increases in steryl lipid content and in the stigmasterol : sitosterol ratio occur with ripening of tomato fruit pericarp tissue (Chow and Jen, 1978; Whitaker, 1988), and these changes coincide with a decrease in the fluidity of plasma membranes (Legge et al., 1986). A similar correlation between increasing microviscosity and an increasing sterol : phospholipid ratio in microsomal membranes during ripening and postharvest senescence of bell pepper fruit pericarp has been reported by Lurie and Ben-Yehoshua (1986). However, in a study of steryl lipid content and composition in bell pepper pericarp from three cultivars, the only change found to occur with ripening was in the ratio of ASG to SG (Whitaker and Lusby, 1989). The present study was undertaken, in part, to determine whether changes in the steryl lipids of microsomal membranes during ripening of bell pepper pericarp differ from those previously observed for total pericarp lipids.

A second objective of the study was to provide a thorough comparison of the polar lipid and steryl lipid composition of purified chloroplasts and chromoplasts from bell pepper pericarp tissue. Pericarp tissue of bell pepper fruit has served as a model in studies of the transformation of chloroplasts to chromoplasts during ripening (Camara and Brangeon, 1981; Spurr and Harris, 1968). The enzyme systems and intermediates involved in carotenogenesis have been studied extensively (Camara and Brangeon, 1981; Camara and Dogbo, 1986; Camara and Moneger,

Received for publication 9 Oct. 1990. Use of a company or product name by the U.S. Dept. of Agriculture (USDA) does not imply approval or recommendation of the product to the exclusion of others that may also be suitable. The author would like to thank John Stommel, USDA/ARS Vegetable Laboratory, Beltsville, Md., for planting and tending the field plots of bell pepper, and Julio Vaquerano for his invaluable technical assistance. The cost of publishing this paper was defrayed in part by the payment of page charges. Under postal regulations, this paper therefore must be hereby marked advertisement solely to indicate this fact.
1982; Camara et al., 1982, 1983). In contrast, there has been relatively little study of changes in membrane lipid composition associated with plastid transformation, despite evidence that the lipid environment in plastid envelope and interior membranes is critical for the final steps in carotenoid synthesis (Camara and Brangeon, 1981; Camara et al., 1982).

During the course of this work, it was noted that growth conditions had a profound influence on the lipid composition of both plastid and microsomal membranes from mature-green and red-ripe bell pepper fruit. These results are discussed with respect to the effects of light and temperature on lipid metabolism.

\section{Materials and Methods}

Fruits of the 'Gator Bell' bell pepper were harvested from greenhouse-grown plants between 28 Apr. and 19 May 1989 and from field-grown plants between 31 Aug. and 22 Sept. 1989. In the greenhouse, natural daylight was supplemented by 400-W high-pressure sodium lamps, which provided a photosynthetic photon flux of 300 to $400 \mu \mathrm{mol} \cdot \mathrm{s}^{-1} \cdot \mathrm{m}^{-2}$ for $14 \mathrm{~h} \cdot \mathrm{day}^{-1}$ $(0600-2000 \mathrm{HR})$. Plants were grown in large pots $(\approx 3$ liters in volume) in a peatmoss and perlite-based commercial potting mixture. Pots were watered daily and nutrient solution (Peter's 14N-14P-14K fertilizer at $1 \mathrm{~g} \cdot \mathrm{liter}^{-1}$; W.R. Grace \& Co., Fogelsville, Pa.) was applied once every 2 weeks. Plants in the field were grown in cultivar trial plots at Beltsville as described by Whitaker and Lusby (1989). Bell pepper fruits were harvested at either the mature-green (pericarp $>95 \%$ green) or redripe (pericarp $>95 \%$ red) stage. The fruits were washed and processed within $2 \mathrm{~h}$ after harvest.

Isolation of plastids and microsomal membranes. Outer pericarp tissue ( $\approx 150 \mathrm{~g}$ fresh weight) from one large or two medium-sized bell peppers was diced and immersed in $125 \mathrm{ml}$ of homogenization medium $(0.33 \mathrm{~m}$ sorbitol, $1 \mathrm{~mm}$ EDTA, $1 \mathrm{~mm}$

Abbreviations: ASG, acylated steryl glycoside; DGDG, digalactosyldiacylglycerol; FS, free sterols; GL, galactolipids; GlyL, glycolipid; MGDG, monogalactosyldiacylglycerol; NL, neutral lipid; PA, phosphatidic acid; PC, phosphatidylcholine; PE, phosphatidylethanolamine; PG, phosphatidylglycerol; PI, phosphatidylinositol; PL, phospholipid; SG, steryl glycoside; TSL, total steryl lipids (FS + ASG + SG). 
B-mercaptoethanol, and $50 \mathrm{~mm}$ Tricine adjusted to $\mathrm{pH} 7.8$ with $\mathrm{KOH})$ at $4 \mathrm{C}$. After equilibration for 15 rein, the diced pericarp tissue was disrupted with a mortar and pestle, followed by filtration of the homogenate through eight layers of cheesecloth and two layers of Miracloth (Calbiochem, La Jolla, Calif.). The filtrate was centrifuged $5 \mathrm{~min}$ at $150 \times \mathrm{g}$ to remove cell debris, followed by centrifugation of the supernatant for $10 \mathrm{~min}$ at $2000 \times$ $\mathrm{g}$ to obtain the crude plastid pellet. The $2000 \times \mathrm{g}$ supernatant was centrifuged $20 \mathrm{~min}$ at $13,000 \times \mathrm{g}$ to obtain a suspension of microsomal membranes. The microsomal suspension was then distributed evenly in eight 30-ml polycarbonate screw-capped tubes, which were placed in a $\mathrm{Ti} 70$ rotor and centrifuged 35 min at $\approx 90,000 \times \mathrm{g}$ in a Beckman L8-55 ultracentrifuge (Beckman Instruments, Palo Alto, Calif.) (at 4C) to pellet the microsomal membranes. The microsomal pellets were resuspended in $20 \mathrm{ml}$ of $20 \mathrm{~mm}$ HEPES buffer, $\mathrm{pH} \mathrm{7.8,} \mathrm{containing} 1 \mathrm{~mm}$ EDTA. Two 20- $\mu 1$ aliquots of the suspension were withdrawn for protein determination by the method of Bradford (1976). The remainder was frozen with liquid nitrogen and stored at - 70C overnight before lipid extraction.

The crude chloroplast or chromoplast pellet (from green or red fruit, respectively) was resuspended in $12 \mathrm{ml}$ of homogenization medium, and purified plastids were isolated by centrifugation on sucrose step gradients (Camara et al., 1983). Two $\mathrm{ml}$ of the plastid suspension was layered on each of six Beckman Ultra-Clear tubes containing (in descending order) $9 \mathrm{ml}$ each of $0.46 \mathrm{M}, 0.84 \mathrm{M}$, and $1.45 \mathrm{M}$ sucrose plus $1 \mathrm{~mm} ß$-mercaptoethanol and $50 \mathrm{~mm}$ Tricine at $\mathrm{pH}$ 7.6. The tubes were inserted in the buckets of an SW 27 rotor and centrifuged for $1 \mathrm{~h}$ at $62,000 \times$ gin a Beckman L8-55 at 4C. The band of largely intact plastids at the $0.84-\mathrm{M}$ to $1.45-\mathrm{M}$ interface was collected from each of the six tubes with a Pasteur pipet. The pooled, purified plastid suspension was then diluted 1 to 1 with $50 \mathrm{~mm}$ Tricine, followed by centrifugation for $5 \mathrm{~min}$ at $4000 \times \mathrm{g}$ to pellet the plastids before lipid extraction.

Lipid extraction, fractionation, and analysis. Microsomal membrane suspensions $(20 \mathrm{ml})$ were extracted with $60 \mathrm{ml}$ of 2 chloroform :1 methanol. Lathosterol $(20 \mu \mathrm{g}$; chlolest-7-en-3ßo1; Sigma, St Louis) was added as an internal free sterol standard. After vigorous mixing and centrifugation, the lipid-containing chloroform phase was washed twice with $16 \mathrm{ml}$ of $0.8 \%$ $\mathrm{NaCl}$ in 1 methanol : 1 water and once with 1 methanol : 1 water. The chloroform phase was evaporated under a stream of nitrogen, and the total microsomal lipids (dissolved in $2 \mathrm{ml}$ of chloroform) were stored at $-70 \mathrm{C}$.

Gradient-purified chloroplasts and chromoplasts were extracted with $16 \mathrm{ml}$ of boiling isopropanol, then with $18 \mathrm{ml}$ of 2 chloroform : 1 methanol. Lathosterol $(10 \mu \mathrm{g})$ was added as an internal sterol standard. After evaporation of the isopropanol from extract 1 under a stream of $\mathrm{N}_{2}$, the two extracts were combined and washed (Folch et al., 1957). Total plastid lipids were stored at $-70 \mathrm{C}$ in $2 \mathrm{ml}$ of chloroform.

Total lipid extracts from both microsomes and plastids were loaded on a silicic acid column in $2 \mathrm{ml}$ of chloroform and separated into. neutral lipid (NL), glycolipid (GlyL), and PL fractions by sequential elution with 20 chloroform : 1 acetone, 20 acetone: 1 methanol, and 10 methanol :1 water. Before column fractionation, two 20- $\mu 1$ aliquots were withdrawn from the microsomal and plastid extracts for either chlorophyll (green fruit) or carotenoid (red fruit) determination. Chlorophyll was quantified spectrophotometrically in $N, N$-dimethylformamide (DMF) (Inskeep and Bloom, 1985). Keto-carotenoids (e.g., capsanthin and capsorubin) were quantified spectrophotometrically in chlo- roform (absorbance maximum $482 \mathrm{~nm}$, extinction coefficient 2100) (Davies, 1976). FS were subfractionated from the NL by elution from a silica Sep-Pak (Waters Assoc., Milford, Mass.) with 2 hexane : 1 diethyl ether, then isolated by precipitation with digitonin (Whitaker, 1988). Individual GlyL (ASG; SG; monogalactosyldiacylglycerols, MGDG; digalactosyldiacylglycerols, DGDG) and PL (phosphatidic acid, PA; phosphatidylethanolamine, PE; phosphatidylglycerol, PG; phosphatidylcholine, PC; phosphatidylinositol, PI) were separated by one-dimensional thin-layer chromatography (TLC) on $20 \times 20-\mathrm{cm}$ glass plates precoated with a $0.25-\mathrm{mm}$ thickness of silica gel 60 (EM Reagents, Darmstadt, Federal Republic of Germany) developed in a solvent mixture of 85 chloroform : 15 methanol :12.5 acetic acid :3.5 water. GlyL and PL were identified by cochromatography with authentic standards (Supelco, Bellefonte, Pa., and Sigma) and by use of spray reagents specific for hexose sugars, phosphate, sterols, primary amines, and choline (Kates, 1986). Lipid spots on the TLC plate were visualized by brief staining (30 see) with iodine vapor, then were scraped and eluted with $3 \mathrm{ml}$ of 2 chloroform :1 methanol, followed by a Folch wash. MGDG and DGDG were quantified by the method of Roughan and Batt (1968). ASG and SG were quantified both by a modification of the method of Zlatkis et al. (1953) and by high-performance liquid chromatography (HPLC) on a 5- $\mu$ Spherisorb C-6 reversed-phase column, as described by Whitaker et a1 (1990). PL were quantified by the method of Ames (1966) for organic phosphate. Identification of sterols by gas chromatography-mass spectrophotometry (GCMS) and determination of the sterol composition of FS by capillary GLC were performed as previously described (Whitaker and Lusby, 1989).

\section{Results}

Composition of microsomes and plastids from green and red pericarp of field- vs. greenhouse-grown fruits. The yield of microsomal protein and PL per $150 \mathrm{~g}$ fresh weight of pericarp was smaller for greenhouse- than for field-grown fruit, but the trend of declining protein and PL levels with ripening was evident under both growth conditions (Table 1). The levels of chlorophyll (green fruit), keto-carotenoids (red fruit), and the galacto-lipids (GL) MGDG and DGDG in the microsomal fractions indicate the extent of contamination by plastid membranes. The yield of chloroplast pigment and lipids from $150 \mathrm{~g}$ of mature-green pericarp was substantially greater for greenhousethan for field-grown fruit (Table 2). In contrast, the yield of chromoplast pigment and lipids (with the exception of steryl lipids) was greater from red-ripe pericarp of field-grown fruit. Under both growth conditions, the amount of GL (MGDG + DGDG) in chromoplasts was greater than that in chloroplasts.

Lipid ratios in microsomes and plastids. Ripening and growth conditions affected various lipid : lipid and lipid : protein ratios in microsomal membranes (Table 3). In microsomes from fieldgrown fruit, the FS : PL, TSL : PL, and TSL : protein ratios increased dramatically with ripening. In contrast, ripening of greenhouse-grown fruit did not alter the microsomal FS : PL ratio, and the TSL : PL and TSL : protein ratios increased only slightly. The PL : protein ratio was somewhat higher in microsomes from greenhouse- vs. field-grown fruit, but this ratio did not change with ripening under either growth condition. The ASG : SG ratio decreased sharply with ripening under both growth conditions, the decline being more dramatic in microsomes from greenhouse-grown fruit. There was a similar increase in the ratio of MGDG to DGDG with ripening of field- 
Table 1. Protein, pigment, and lipid content of microsomal membranes isolated from $150 \mathrm{~g}$ fresh weight of pericarp tissue from 'Gator Bell' bell pepper fruit harvested at the maturegreen or red-ripe stage and grown in a greenhouse or in field plots.

\begin{tabular}{|c|c|c|c|c|}
\hline \multirow[b]{3}{*}{ Constituent ${ }^{z}$} & \multicolumn{4}{|c|}{ Source of fruit } \\
\hline & \multicolumn{2}{|c|}{ Field } & \multicolumn{2}{|c|}{ Greenhouse } \\
\hline & Mature-green & Red-ripe & Mature-green & Red-ripe \\
\hline Protein ${ }^{*}$ & $9.60 \pm 0.64$ & $6.62 \pm 0.64$ & $6.70 \pm 1.02$ & $4.35 \pm 0.33$ \\
\hline Chlorophyll* & $0.021 \pm 0.006$ & -.- & $0.042 \pm 0.004$ & -.. \\
\hline Carotenoids* & -.. & $0.31 \pm 0.05$ & --- & $0.31 \pm 0.10$ \\
\hline FS & $0.84 \pm 0.08$ & $0.82 \pm 0.05$ & $1.63 \pm 0.17$ & $1.06 \pm 0.06$ \\
\hline ASG & $0.52 \pm 0.07$ & $0.64 \pm 0.01$ & $0.92 \pm 0.16$ & $0.44 \pm 0.09$ \\
\hline SG & $0.53 \pm 0.08$ & $1.46 \pm 0.09$ & $0.35 \pm 0.06$ & $0.72 \pm 0.05$ \\
\hline $\mathrm{PL}$ & $5.34 \pm 0.45$ & $3.59 \pm 0.28$ & $4.97 \pm 0.72$ & $3.37 \pm 0.34$ \\
\hline MGDG & $0.33 \pm 0.05$ & $0.81 \pm 0.16$ & $0.50 \pm 0.05$ & $0.67 \pm 0.13$ \\
\hline DGDG & $0.71 \pm 0.11$ & $0.85 \pm 0.13$ & $1.30 \pm 0.27$ & $0.62 \pm 0.02$ \\
\hline
\end{tabular}

${ }^{z}$ Values for protein, total chlorophyll, and keto-carotenoids (absorbance maximum $\approx 480 \mathrm{~nm}$, mainly capsanthin and capsorubin) are expressed in milligrams $\pm \mathrm{SD}$, as denoted by $\left({ }^{*}\right)$. All other values are expressed in micromoles $\pm S D(n=4)$.

Table 2. Pigment and lipid content of chloroplasts and chromoplasts isolated from $150 \mathrm{~g}$ fresh weight of pericarp tissue from 'Gator Bell' bell pepper fruit harvested at the mature-green and red-ripe stages, respectively, and grown in a greenhouse or in field plots.

\begin{tabular}{|c|c|c|c|c|}
\hline \multirow[b]{3}{*}{ Constituent ${ }^{z}$} & \multicolumn{4}{|c|}{ Source of fruit } \\
\hline & \multicolumn{2}{|c|}{ Field } & \multicolumn{2}{|c|}{ Greenhouse } \\
\hline & $\begin{array}{c}\text { Mature-green } \\
\text { chloroplasts }\end{array}$ & $\begin{array}{c}\text { Red-ripe } \\
\text { chromoplasts }\end{array}$ & $\begin{array}{c}\text { Mature-green } \\
\text { chloroplasts }\end{array}$ & $\begin{array}{c}\text { Red-ripe } \\
\text { chromoplasts }\end{array}$ \\
\hline Chlorophyll* & $0.38 \pm 0.03$ & -- & $0.61 \pm 0.06$ & -- \\
\hline Carotenoids* & --- & $2.59 \pm 0.30$ & --- & $1.67 \pm 0.17$ \\
\hline FS & $0.12 \pm 0.02$ & $0.04 \pm 0.01$ & $0.32 \pm 0.12$ & $0.11 \pm 0.05$ \\
\hline ASG & $0.12 \pm 0.02$ & $0.03 \pm 0.00$ & $0.23 \pm 0.07$ & $0.08 \pm 0.02$ \\
\hline SG & $0.04 \pm 0.01$ & $0.09 \pm 0.01$ & $0.08 \pm 0.03$ & $0.06 \pm 0.01$ \\
\hline $\mathrm{PL}$ & $0.34 \pm 0.01$ & $0.61 \pm 0.04$ & $1.19 \pm 0.36$ & $0.46 \pm 0.14$ \\
\hline MGDG & $0.91 \pm 0.05$ & $3.16 \pm 0.33$ & $1.36 \pm 0.20$ & $1.86 \pm 0.35$ \\
\hline DGDG & $0.73 \pm 0.04$ & $1.68 \pm 0.18$ & $0.94 \pm 0.20$ & $1.01 \pm 0.20$ \\
\hline
\end{tabular}

${ }^{2}$ Values for total chlorophyll and keto-carotenoids (absorbance) maximum $\approx 480 \mathrm{~nm}$, mainly capsanthin and capsorubin) are expressed in milligrams $\pm \mathrm{SD}$, as denoted by $\left(^{*}\right)$. All other values are expressed in micromoles $\pm \operatorname{SD}(n=4)$.

Table 3. Lipid : lipid (mol : mol) and lipid : protein ( $\mu \mathrm{mol}: \mathrm{mg}$ ) ratios in microsomal membranes isolated from pericarp tissue of field- or greenhouse-grown 'Gator Bell' bell pepper fruit harvested at the mature-green or red-ripe stage.

\begin{tabular}{|c|c|c|c|c|}
\hline \multirow[b]{3}{*}{ Ratio $^{z}$} & \multicolumn{4}{|c|}{ Source of fruit } \\
\hline & \multicolumn{2}{|c|}{ Field } & \multicolumn{2}{|c|}{ Greenhouse } \\
\hline & Mature-green & Red-ripe & Mature-green & Red-ripe \\
\hline FS : PL & $0.16 \pm 0.01$ & $0.23 \pm 0.01$ & $0.33 \pm 0.02$ & $0.32 \pm 0.04$ \\
\hline TSL : PL & $0.35 \pm 0.02$ & $0.81 \pm 0.03$ & $0.59 \pm 0.01$ & $0.66 \pm 0.09$ \\
\hline TSL : protein & $0.20 \pm 0.02$ & $0.44 \pm 0.02$ & $0.44 \pm 0.01$ & $0.51 \pm 0.05$ \\
\hline PL : protein & $0.56 \pm 0.02$ & $0.54 \pm 0.01$ & $0.74 \pm 0.01$ & $0.77 \pm 0.03$ \\
\hline ASG : SG & $0.99 \pm 0.08$ & $0.44 \pm 0.02$ & $2.65 \pm 0.28$ & $0.62 \pm 0.18$ \\
\hline MGDG : DGDG & $0.47 \pm 0.06$ & $0.95 \pm 0.11$ & $0.40 \pm 0.08$ & $1.09 \pm 0.20$ \\
\hline
\end{tabular}

${ }^{\mathrm{z}}$ Values represent the mean \pm SD $(n=4)$.

and greenhouse-grown fruit. This increase reflects the increase in the MGDG : DGDG ratio that occurred with the chloroplast to chromoplast transformation regardless of growth conditions (Table 4). It is notable, however, that the MGDG : DGDG ratio was consistently lower in microsomes than in plastids (Tables 3 and 4), which may indicate contamination of the microsomal fraction with plastid envelopes (Douce and Joyard, 1979).

Both the FS : PL and TSL : PL ratios declined sharply with the transformation of chloroplasts to chromoplasts infield-grown fruit, whereas the FS : PL ratio declined only slightly and the TSL : PL ratio did not change in plastids of greenhouse-grown fruit (Table 4). The GL : PL ratio was higher in plastids of field- vs. greenhouse-grown fruit, but increased sharply with plastid transformation under both growth conditions. This increase was accompanied by an increase in the MGDG : DGDG ratio. The ASG : $S G$ ratio in plastids decreased sharply with ripening under both growth conditions, but most dramatically in field-grown fruit. The chlorophyll $\mathrm{a}: \mathrm{b}$ and GL : chlorophyll 
Table 4. Lipid : lipid (mol : mol), lipid : pigment ( $\mu \mathrm{mol}: \mathrm{mg}$ ), and chlorophyll a : b (mg : mg) ratios in plastids isolated from pericarp tissue of field- or greenhouse-grown 'Gator Bell' bell pepper fruit harvested at the mature-green or red-ripe stage.

\begin{tabular}{|c|c|c|c|c|}
\hline \multirow[b]{3}{*}{ Ratio $^{2}$} & \multicolumn{4}{|c|}{ Source of fruit } \\
\hline & \multicolumn{2}{|c|}{ Field } & \multicolumn{2}{|c|}{ Greenhouse } \\
\hline & $\begin{array}{c}\text { Mature-green } \\
\text { chloroplasts }\end{array}$ & $\begin{array}{c}\text { Red-ripe } \\
\text { chromoplasts }\end{array}$ & $\begin{array}{c}\text { Mature-green } \\
\text { chloroplasts }\end{array}$ & $\begin{array}{c}\text { Red-ripe } \\
\text { chromoplasts }\end{array}$ \\
\hline Chl a:b & $2.19 \pm 0.05$ & $\ldots$ & $2.10 \pm 0.03$ & $\ldots$ \\
\hline FS : PL & $0.35 \pm 0.08$ & $0.07 \pm 0.01$ & $0.29 \pm 0.03$ & $0.22 \pm 0.04$ \\
\hline TSL : PL & $0.80 \pm 0.15$ & $0.28 \pm 0.01$ & $0.55 \pm 0.04$ & $0.54 \pm 0.04$ \\
\hline GL : PL & $4.81 \pm 0.35$ & $7.97 \pm 0.80$ & $2.05 \pm 0.45$ & $6.47 \pm 0.84$ \\
\hline GL : chlorophyll & $4.29 \pm 0.22$ & --- & $3.67 \pm 0.22$ & - \\
\hline GL : carotenoids & --- & $1.87 \pm 0.08$ & -. & $1.75 \pm 0.37$ \\
\hline ASG : SG & $2.88 \pm 0.45$ & $0.33 \pm 0.04$ & $2.63 \pm 0.19$ & $1.30 \pm 0.29$ \\
\hline MGDG : DGDG & $1.26 \pm 0.02$ & $1.88 \pm 0.05$ & $1.42 \pm 0.03$ & $1.84 \pm 0.09$ \\
\hline
\end{tabular}

${ }^{2}$ Values represent the mean \pm SD $(n=4)$.

ratios in chloroplasts, and the GL : carotenoid ratio in chromoplasts, were similar under the two growth conditions.

Proportions of steryl lipids in plastids and microsomes. Ripening and growth conditions influenced the relative amounts of FS, ASG, and SG in plastids and microsomal membranes (Table 5). In both subcellular fractions under both growth conditions, changes in the steryl lipid distribution with ripening followed the same trend; SG increased while ASG and FS decreased. These changes were much more pronounced in plastids and microsomes from field-grown fruit. Regardless of the growth conditions, the proportions of FS, ASG, and SG were fairly similar in plastids and microsomes from the same fruit. The proportions of steryl lipids in chloroplasts and microsomes from mature-green pericarp of field-grown fruit were similar to those in chromoplasts and microsomes from red-ripe pericarp of greenhouse-grown fruit.

Free sterol composition of microsomes and plastids. The FS composition of comparable microsomal fractions was closely similar for field- and greenhouse-grown fruit (Table 6). Similar changes in microsomal FS occurred with ripening under the two growth conditions, including small decreases in the major sterols, campesterol and sitosterol, that were offset by increases in a few minor sterols (mostly intermediates of sitosterol synthesis). The FS compositions of comparable plastid fractions (chloroplasts or chromoplasts) were also closely similar under the two growth conditions (Table 6). Changes in plastid FS during the chloroplast to chromoplast transformation included decreases in. campesterol and sitosterol that were offset by increases in cholesterol and several minor C-29 phytosterols. In general, the changes in FS composition associated with ripening were more pronounced in plastids than in microsomes. The sterol composition of ASG and SG was not determined in this study.
Previous results showed that in green, turning, and red fruits, the sterol composition of ASG and SG differed only slightly from that of FS (Whitaker and Lusby, 1989).

Phospholipid composition of microsomes and plastids. The PL composition of microsomal membranes was closely similar for field- and greenhouse-grown fruit, and there was very little change observed with ripening (Table 7). The level of PI was lower, and the levels of the minor PL, PG and PA, were slightly higher in microsomes from greenhouse-grown fruit. Effects of growth conditions and ripening on the PL composition of plastids were far more pronounced (Table 7). Under both growth conditions, a large increase in PC and sharp decreases in PE and PA occurred during plastid transformation. As noted for microsomes, the level of PI was lower and the level of PA was higher in plastids from greenhouse-grown fruit. The level of PG, a major PL in plastids, was higher in chloroplasts yet lower in chromoplasts of field- compared to greenhouse-grown fruit. Hence, during plastid transformation, plastid PG declined in field-grown but increased in greenhouse-grown fruit.

\section{Discussion}

A decrease in membrane fluidity has been reported to occur with ripening of fruits and with senescence in other plant tissues (Legge et al., 1986; Lurie and Ben-Arie, 1983; Lurie and BenYehoshua, 1986; Thompson et al., 1982). Studies of changes in membrane lipid composition during ripening and senescence have indicated that an increase in the sterol : phospholipid ratio may account, at least in part, for the decrease in membrane fluidity associated with these phenomena (Borochov et al., 1982; Lurie and Ben-Arie, 1983; Lurie and Ben-Yehoshua, 1986; Thompson et al., 1982; Whitaker, 1988). A close correlation between increased sterol content and increased viscosity of mi-

Table 5. Proportions of individual steryl lipids in plastids and microsomal membranes isolated from pericarp tissue of field- or greenhousegrown 'Gator Bell' bell pepper fruit harvested at the mature-green or red-ripe stage.

\begin{tabular}{|c|c|c|c|c|c|c|c|c|}
\hline \multirow[b]{3}{*}{$\begin{array}{l}\text { Steryl } \\
\text { lipid }^{z}\end{array}$} & \multicolumn{8}{|c|}{ Source of fruit } \\
\hline & \multicolumn{4}{|c|}{ Field } & \multicolumn{4}{|c|}{ Greenhouse } \\
\hline & $\begin{array}{l}\text { Mature-green } \\
\text { chloroplasts }\end{array}$ & $\begin{array}{c}\text { Red-ripe } \\
\text { chromoplasts }\end{array}$ & $\begin{array}{c}\text { Mature-green } \\
\text { microsomes }\end{array}$ & $\begin{array}{l}\text { Red-ripe } \\
\text { microsomes }\end{array}$ & $\begin{array}{c}\text { Mature-green } \\
\text { chloroplasts }\end{array}$ & $\begin{array}{c}\text { Red-ripe } \\
\text { chromoplasts }\end{array}$ & $\begin{array}{c}\text { Mature-green } \\
\text { microsomes }\end{array}$ & $\begin{array}{l}\text { Red-ripe } \\
\text { microsomes }\end{array}$ \\
\hline FS & 42 & 25 & 44 & 28 & 53 & 44 & 56 & 48 \\
\hline ASG & 42 & 19 & 28 & 22 & 34 & 32 & 32 & 20 \\
\hline SG & 16 & 56 & 28 & 50 & 13 & 24 & 12 & 32 \\
\hline
\end{tabular}

${ }^{z}$ Values represent the mole percentage of TSL in each membrane fraction. 
Table 6. FS composition of plastids and microsomal membranes isolated from pericarp tissue of field- or greenhouse-grown 'Gator Bell' bell pepper fruit harvested at the mature-green or red-ripe stage.'

\begin{tabular}{|c|c|c|c|c|c|c|c|c|}
\hline \multirow[b]{3}{*}{ Sterol } & \multirow{2}{*}{\multicolumn{2}{|c|}{$\begin{array}{l}\text { Microsomal membranes from } \\
\text { field-grown fruit } \\
\end{array}$}} & \multirow{2}{*}{\multicolumn{2}{|c|}{$\begin{array}{l}\text { Microsomal membranes from } \\
\text { greenhouse-grown fruit }\end{array}$}} & \multicolumn{2}{|c|}{$\begin{array}{l}\text { Plastids from } \\
\text { field-grown fruit }\end{array}$} & \multicolumn{2}{|c|}{$\begin{array}{c}\text { Plastids from } \\
\text { greenhouse-grown fruit }\end{array}$} \\
\hline & & & & & \multirow{2}{*}{$\begin{array}{l}\text { Mature-green } \\
\text { chloroplasts }\end{array}$} & \multirow{2}{*}{$\begin{array}{c}\text { Red-ripe } \\
\text { chromoplasts }\end{array}$} & \multirow{2}{*}{$\begin{array}{c}\text { Mature-green } \\
\text { chloroplasts }\end{array}$} & \multirow{2}{*}{$\begin{array}{c}\text { Red-ripe } \\
\text { chromoplasts }\end{array}$} \\
\hline & Mature-green & Red-ripe & Mature-green & Red-ripe & & & & \\
\hline Cholesterol & $1.3 \pm 0.2$ & $1.5 \pm 0.1$ & $0.9 \pm 0.1$ & $1.1 \pm 0.1$ & $3.7 \pm 0.4$ & $10.3 \pm 0.6$ & $2.4 \pm 0.4$ & $6.8 \pm 0.5$ \\
\hline Campesterol & $24.1 \pm 0.9$ & $20.3 \pm 0.7$ & $22.9 \pm 0.8$ & $19.6 \pm 1.1$ & $25.3 \pm 0.9$ & $18.7 \pm 0.5$ & $24.5 \pm 0.4$ & $17.0 \pm 0.7$ \\
\hline Stigmasterol & $3.1 \pm 0.2$ & $3.5 \pm 0.2$ & $3.2 \pm 0.5$ & $3.6 \pm 0.6$ & $4.9 \pm 0.5$ & $4.8 \pm 0.6$ & $4.8 \pm 0.7$ & $5.4 \pm 0.6$ \\
\hline Sitosterol & $68.6 \pm 0.9$ & $65.7 \pm 0.3$ & $70.5 \pm 1.1$ & $69.2 \pm 1.1$ & $63.7 \pm 0.8$ & $55.0 \pm 0.3$ & $66.2 \pm 0.8$ & $60.7 \pm 0.6$ \\
\hline Others $^{y}$. & $2.9 \pm 0.1$ & $9.0 \pm 1.2$ & $2.4 \pm 0.6$ & $6.6 \pm 0.9$ & $2.4 \pm 0.4$ & $11.2 \pm 1.6$ & $2.1 \pm 0.2$ & $10.2 \pm 0.7$ \\
\hline
\end{tabular}

${ }^{2}$ Values represent the mean weight percentage of TSL \pm SD $(n=4)$.

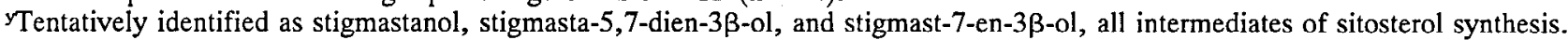

Table 7. PL composition of plastids and microsomal membranes isolated from pericarp tissue of field- or greenhouse-grown 'Gator Bell' bell pepper fruit harvested at the mature-green or red-ripe stage. ${ }^{\mathbf{z}}$

\begin{tabular}{|c|c|c|c|c|c|c|c|c|}
\hline \multirow[b]{3}{*}{ Phospholipid } & \multirow{2}{*}{\multicolumn{2}{|c|}{$\begin{array}{l}\text { Microsomal membranes from } \\
\text { field-grown fruit }\end{array}$}} & \multirow{2}{*}{\multicolumn{2}{|c|}{$\begin{array}{l}\text { Microsomal membranes from } \\
\text { greenhouse-grown fruit }\end{array}$}} & \multicolumn{2}{|c|}{$\begin{array}{l}\text { Plastids from } \\
\text { field-grown fruit }\end{array}$} & \multicolumn{2}{|c|}{$\begin{array}{c}\text { Plastids from } \\
\text { greenhouse-grown fruit }\end{array}$} \\
\hline & & & & & \multirow{2}{*}{$\begin{array}{l}\text { Mature-green } \\
\text { chloroplasts }\end{array}$} & \multirow{2}{*}{$\begin{array}{c}\text { Red-ripe } \\
\text { chromoplasts }\end{array}$} & \multirow{2}{*}{$\begin{array}{c}\text { Mature-green } \\
\text { chloroplasts }\end{array}$} & \multirow{2}{*}{$\begin{array}{c}\text { Red-ripe } \\
\text { chromoplasts }\end{array}$} \\
\hline & Mature-green & Red-ripe & Mature-green & Red-ripe & & & & \\
\hline PI & $10.4 \pm 1.0$ & $11.3 \pm 1.2$ & $6.4 \pm 0.3$ & $7.0 \pm 0.8$ & $12.4 \pm 1.4$ & $14.8 \pm 2.3$ & $9.8 \pm 0.8$ & $7.6 \pm 0.9$ \\
\hline $\mathrm{PC}$ & $58.1 \pm 1.1$ & $56.3 \pm 0.6$ & $57.9 \pm 1.2$ & $58.6 \pm 0.6$ & $33.7 \pm 1.2$ & $58.6 \pm 2.4$ & $40.0 \pm 1.5$ & $50.6 \pm 1.9$ \\
\hline PG & $1.8 \pm 0.1$ & $2.2 \pm 0.1$ & $2.3 \pm 0.4$ & $2.6 \pm 0.1$ & $24.7 \pm 0.9$ & $14.3 \pm 0.8$ & $13.2 \pm 2.6$ & $21.6 \pm 4.6$ \\
\hline PE & $28.5 \pm 0.1$ & $28.5 \pm 0.9$ & $31.1 \pm 1.1$ & $29.2 \pm 1.4$ & $24.8 \pm 1.8$ & $11.4 \pm 0.7$ & $24.7=1.4$ & $14.0 \pm 2.5$ \\
\hline PA & $1.2 \pm 0.2$ & $1.7 \pm 0.3$ & $2.3 \pm 0.1$ & $2.6 \pm 0.3$ & $4.4 \pm 0.6$ & $0.9 \pm 0.1$ & $12.3 \pm 0.3$ & $6.2 \pm 1.2$ \\
\hline
\end{tabular}

${ }^{2}$ Values represent the mean mole percentage of total $\mathrm{PL} \pm \mathrm{SD}(\mathrm{n}=4)$.

crosomal membranes during senescence of both green and red bell pepper fruit was reported by Lurie and Ben-Yehoshua (1986). The same study showed the sterol content of microsomal membranes to be 1.8-fold greater in red than in green fruit at the time of harvest. However, a subsequent study of the steryl lipids of bell pepper fruit showed no significant difference in the content of either FS or TSL in mature-green compared to red-ripe pericarp tissue (Whitaker and Lusby, 1989). The data in Tables 1-4 provide an explanation for this apparent contradiction. In agreement with the report of Lurie and Ben-Yehoshua (1986), we show a large increase in both the FS : PL and TSL : PL ratios in microsomal membranes of field-grown fruit with ripening (Table 3). The opposite changes occurred in plastids with ripening of field-grown fruit, i.e., both the FS : PL and TSL : $\mathrm{PL}$ ratios declined sharply during the chloroplast to chromoplast transformation (Table 4). Thus, in an extract of total pericarp lipids, opposite changes in the steryl lipid content of microsomes and plastids cancel each other, resulting in no net change in the steryl lipid : PL ratio.

It is also noteworthy that FS constituted a substantially smaller percentage of TSL in both microsomes and plastids (Table 5) than what was previously found for extracts of total pericarp lipids (Whitaker and Lusby, 1989). This difference could be attributed to differing growth conditions in the field during the two studies, particularly in light of the dramatic effects of growth conditions on membrane steryl lipid content and composition reported here. Alternatively, the plastid and microsomal membrane fractions may be enriched in ASG and SG relative to other cellular membranes discarded during the fractionation procedure. The ubiquitous occurrence of SG in plant tissues, including meristems, has led to the conclusion that, like FS, ASG and SG are membrane structural lipids (Eichenberger, 1977; Kalinowska and Wojciechowski, 1986; Mudd, 1980). Also, based on the demonstration that FS, SG, and ASG are rapidly inter- converted in plant tissues, it has been suggested that such interconversion could play a role in various developmental processes through alteration of the physical properties and enzymatic activities of cell membranes (Kalinowska and Wojciechowski, 1986; Mudd et al., 1984; Wojciechowski, 1980). In both this and a previous study (Whitaker and Lusby, 1989), a sharp decline in the ASG : SG ratio was associated with ripening of bell pepper pericarp tissue. In the present study, the shift in ASG : SG was shown to occur both in microsomal membranes and in plastids, regardless of the growth conditions. By inference, deacylation of ASG (and perhaps glycosylation of FS) could be involved in the regulation of ripening in bell pepper.

The changes in glycerolipid composition during plastid transformation determined in this study differ from those previously reported by Camara and Brangeon (1981). In particular, we showed an increase in the GL : PL ratio, whereas they showed a decrease in GL : PL. This discrepancy can be attributed to contamination of the chromoplast preparations used in the earlier investigation with other cell membranes due to the inclusion of $10 \mathrm{~mm} \mathrm{MgC1} 1_{2}$ in the isolation medium. Indeed, the GL and $\mathrm{PL}$ contents of chromoplasts isolated in the absence of $\mathrm{MgCl}_{2}$ by Camara et al. (1983) and the GL : PL ratio calculated from their data were much more similar to those reported here. In the present study, it was found that the MGDG : DGDG ratio increased with ripening in both the plastid and microsomal fractions, regardless of the growth conditions (Tables 3 and 4). In accordance with these data, Camara and Brangeon (1981) reported that the rate of labeling of MGDG relative to DGDG by UDP- $\left[{ }^{14} \mathrm{C}\right.$-labelled]galactose was more than 8-fold higher in chromoplasts compared to chloroplasts.

The comparative data on the glycerolipid composition of chloroplasts and chromoplasts from this study do raise some. question as to the relative purity of the different plastid isolates. Specifically, the higher percentage of PE and the lower GL : 
PL ratio in chloroplasts could be taken as an indication of greater contamination. Based on studies of leaf chloroplast lipids, PE is generally regarded as a nonchloroplastic PL. However, a prior study has shown that glycerolipid metabolism is quite different in fruit and leaf chloroplasts from bell pepper (Whitaker, 1986). The same study indicated that the PE content is higher and the GL : PL ratio is lower in fruit compared to leaf chloroplasts, but these data were derived from crude plastid preparations. Assay of marker enzymes for other cell membranes would be required to further evaluate the relative purity of chloroplast and chromoplast fractions prepared by the identical sucrose step gradient procedure.

The growth conditions in the two series of experiments reported here were radically different. In the first series, seedlings were planted in the greenhouse in the winter and fruits were harvested in midspring. The photoperiod was maintained on a 14-h light/10-h dark cycle. Natural daylight, as well as the average day and night temperatures, increased throughout growth, development, and ripening. In the second series, seedlings were transplanted from the greenhouse to field plots in midspring and fruits were harvested in late summer. The plants experienced natural daylight, including ultraviolet irradiation. The photoperiod increased during early growth, then decreased through the remainder of growth, fruit-set, and fruit ripening. Average day and night temperatures also increased initially then tapered off during the weeks of harvest. The combination of these differences in environmental factors had a profound influence on the lipid content and composition of plastids and microsomal membranes. It is not possible at this point' to say which factors were most influential. Previous studies have shown that spectral quality has a marked effect on carotenoid content and composition in Capsicum annuum fruit (Lopez et al., 1986), and that daylength affects the size and number of starch grains in leaves of mature bell pepper plants (Grange et al., 1989).

The most striking differences in the lipids of field- and greenhouse-grown fruit were in the relative proportions of FS, ASG, and SG (Table 5) and in the steryl lipid: PL ratios (Tables 3 and 4). In general, the changes in microsomal and plastid lipids associated with ripening were more pronounced in field-grown fruit, despite the fact that in both series of experiments red fruit were harvested from 10 to 20 days after green fruit. These changes may have resulted from the much greater fluctuations in light and temperature in the field during the weeks of maturation and ripening. It will be of interest in future studies to find whether the effects of growth conditions on membrane lipid composition can be reproduced, and if so, to test what effect the lipid differences have on the postharvest storage life of mature-green and red-ripe fruit.

\section{Literature Cited}

Ames, B.N. 1966. Assay of inorganic phosphate, total phosphate and phosphatases. Methods Enzymol. 8:115-118.

Bradford, M.M. 1976. A rapid and sensitive method for the quantitation of microgram quantities of protein utilizing the principle of protein dye binding. Anal. Biochem. 72:248-254.

Borochov, A., A.H. Halevy, and M. Shinitzky. 1982. Senescence and the fluidity of rose petal membranes. Plant Physiol. 69:296-299.

Camara, B. and J. Brangeon. 1981. Carotenoid metabolism during chloroplast to chromoplast transformation in Capsicum annuum fruit. Planta 151:359-364.

Camara, B. and O. Dogbo. 1986. Demonstration and solubilization of lycopene cyclase from Capsicum chromoplast membranes. Plant Physiol 80:172-174.

Camara, B., F. Bardat, O. Dogbo, J. Brangeon, and R. Moneger. 1983.
Terpenoid metabolism in plastids: Isolation and biochemical characterization of Capsicum annuum chromoplasts. Plant Physiol. 73:94-99.

Camara, B., F. Bardat, and R. Moneger. 1982. Sites of biosynthesis of carotenoids in Capsicum chromoplasts. Eur. J. Biochem. 127:255-258.

Camara, B. and R. Moneger. 1982. Biosynthetic capabilities and localization of enzymatic activities in carotenoid metabolism of Capsicum annuum isolated chromoplasts. Physiol. Veg. 20:757-773.

Chow, E.T.S. and J.J. Jen. 1978. Phytosterol biosynthesis in ripening tomatoes. J. Food Sci. 43:1424-1426.

Davies, B.H. 1976. Carotenoids, p. 149-154. In: T.W. Goodwin (cd.). Chemistry and biochemistry of plant pigments. Academic, London.

Deuce, R. and J. Joyard. 1979. Structure and function of the plastid envelope. Adv. Bet. Res. 7:1-115.

Eichenberger, W. 1977. Steryl glycosides and acylated steryl glycosides, p. 169-182. In: M. Tevini and H.K. Lichtenthaler (eds.). Lipids and lipid polymers in higher plants. Springer, Berlin.

Folch, J., M. Lees, and G.H. Sloane-Stanley. 1957. A simple method for the isolation and purification of total lipids from animal tissues. J. Biol. Chem. 226:497-509.

Grange, R. I., J.B.W. Hammond, and J. Andrews. 1989. Characteristics of starch grains isolated from mature pepper leaves grown under different irradiances and daylengths. J. Expt. Bet. 40:1045-1052.

Inskeep, W.P. and P.R. Bloom. 1985. Extinction coefficients of chlorophyll a and $\mathrm{b}$ in N, N-dimethylformamide and $80 \%$ acetone. Plant Physiol. 77:483-485.

Kalinowska, M. and Z.A. Wojciechowski. 1986. Modulation of activities of steryl glucoside hydrolase and UDPG:sterol glucosyltransferase from Sinapis alba by detergents and lipids. Photochemistry 25:45-49.

Kates, M. 1986. Techniques of lipidology Isolation, analysis and identification of lipids. Elsevier, Amsterdam. p. 239-246.

Legge, R. L., K.-H. Cheng, J.R. Lepock, and J.E. Thompson. 1986. Differential effects of senescence on the molecular organization of membranes in ripening tomato fruit. Plant Physiol. 81:954-959.

Lopez, M., E. Candela, and F. Sabater. 1986. Carotenoids from Capsicum annuum fruits: Influence of spectral quality of radiation. Biol Plant. 28:100-104.

Lurie, S. and R. Ben-Arie. 1983. Microsomal membrane changes during the ripening of apple fruit. Plant Physiol. 73:636-638.

Lurie, S. and S. Ben-Yehoshua. 1986. Changes in membrane properties and abscisic acid during senescence of harvested bell pepper fruit. J. Amer. Soc. Hort. Sci. 111:886-889.

Mudd, J.B. 1980. Sterol interconversion, p. 509-534. In: P.K. Stumpf (cd.). The biochemistry of plants. vol. 4. Academic, New York.

Mudd, J. B., C.H. Moller, and R.E. Garcia. 1984. Biosynthesis and function of sterol derivatives in higher plants, p. 349-366. In: W.D. Nes, G. Fuller, and L.-S. Tsai (eds.). Isopentenoids in plants. Marcel Dekker, New York.

Roughan, P.G. and R.D. Batt. 1968. Quantitative analysis of sulfolipid (sulfoquinovosyl diglyceride) and galactolipids (monogalactosyl and digalactosyl diglycerides) in plant tissues. Anal. Biochem. 22:74-88.

Spurr, A.R. and W.M. Harris. 1968. Ultrastructure of chloroplasts and chromoplasts in Capsicum annuum: I. Thylakoid membrane changes during fruit ripening. Amer. J. Bet. 55:1210-1224.

Thompson, J. E., S. Mayak, M. Shinitzky, and A.H. Halevy. 1982. Acceleration of membrane senescence in cut carnation flowers by treatment with ethylene. Plant Physiol. 69:859-863.

Whitaker, B.D. 1986. Fatty-acid composition of polar lipids in fruit and leaf chloroplasts of "16:3"- and "18:3" -plant species. Planta 169:313319.

Whitaker, B.D. 1988. Changes in the steryl lipid content and composition of tomato fruit during ripening. Photochemistry 27:3411-3416.

Whitaker, B. D., E.H. Lee, and R.A. Rowland. 1990. EDU and ozone protection: Foliar glycerolipids and steryl lipids in snapbean exposed to $\mathrm{O}_{3}$. Physiol. Plant. 80:286-293.

Whitaker, B.D. and W.R. Lusby. 1989. Steryl lipid content and composition in bell pepper fruit at three stages of ripening. J. Amer. Soc. Hort. Sci. 114:648-651.

Wojciechowski, Z.A. 1980. Biosynthesis of sterol conjugates in plants, p. 405-414. In: P. Mazliak, P. Benveniste, C. Costes, and R. Deuce (eds.). Biogenesis and function of plant lipids. Elsevier/North-Holland, Amsterdam.

Zlatkis, A., B. Zak, and A.J. Boyle. 1953. A new method for the direct determination of serum cholesterol. J. Lab. Clinical Medicine 41:486-492. 